\title{
Amelioration of Endothelial Dysfunction and Inflammation in Type 2 Diabetic Patients after Black Seed Oil Supplementation
}

\author{
Amany Talaat Elgarf ${ }^{a *}$, Maram M. Aboromia ${ }^{b}$, Nagwa A. Sabri ${ }^{a}$, Sara Mahmoud Shaheen ${ }^{a}$ \\ ${ }^{a}$ Department of Clinical Pharmacy, Faculty of Pharmacy, Ain Shams University, Cairo 11566, Egypt \\ ${ }^{\mathrm{b}}$ Department of Internal Medicine and Endocrinology, Faculty of Medicine, Ain Shams University, Cairo 11591, \\ Egypt
}

\begin{abstract}
Endothelial dysfunction is a crucial contributor to the development of vascular problems. Nigella sativa L. seed oil which is commonly known as black seed oil is an antioxidant, anti-inflammatory, and hypoglycemic agent that can be considered as an attractive candidate for improving endothelial dysfunction. Our objective is to evaluate the impact of Nigella sativa seed oil on intercellular adhesion molecule-1 (ICAM-1) and high sensitivity c-reactive protein (hsCRP), as well as the quality of life of type 2 diabetic patients. A prospective, randomized, placebocontrolled, double-blinded study was conducted and registered in ClinicalTrials.gov (NCT03959306). Patients were randomly given either $1800 \mathrm{mg} /$ day of black seed oil or placebo capsules for 12 weeks. Full clinical history, biochemical glycemic indices, lipid profile, kidney and liver functions, hsCRP, ICAM-1, as well as diabetes-39 questionnaire were assessed at baseline and end of the study. After 12 weeks, the levels of hemoglobin A1C, total cholesterol, triglycerides, hsCRP, and ICAM-1, as well as diabetes control domain scores decreased significantly in the intervention group compared to the control group. In conclusion, the administration of black seed oil over 12 weeks showed superior efficacy over standard treatment alone in the management of type 2 diabetes mellitus and can be considered as a therapeutic option for improving endothelial dysfunction.
\end{abstract}

Keywords: Type 2 diabetes mellitus; Black seed oil; Endothelial dysfunction; Intercellular adhesion molecule-1; High sensitivity c-reactive protein; Quality of life.

*Correspondence | Amany Talaat Elgarf, Department of Clinical Pharmacy, Faculty of Pharmacy, Ain Shams University, Cairo 11566, Egypt. Email: amany abdelatif@pharma.asu.edu.eg

Citation | Elgarf AT, Aboromia MM, Sabri NA, Shaheen SM, 2021. Amelioration of Endothelial Dysfunction and Inflammation in Type 2 Diabetic Patients after Black Seed Oil Supplementation. Arch Pharm Sci ASU 5(2): 317-330

DOI: $10.21608 /$ aps.2021.108852.1074

Print ISSN: 2356-8380. Online ISSN: 2356-8399.

Received 01 December 2021. Accepted 15 December 2021.

Copyright: ${ }^{{ }^{2}} 2021$ Elgarf et al. This is an open-access article licensed under a Creative Commons Attribution 4.0 International License (CC BY 4.0), which permits unrestricted use, distribution, and reproduction in any medium, provided the original author(s) and source are credited. Published by: Ain Shams University, Faculty of Pharmacy

\section{Introduction}

Glucotoxicity, lipotoxicity, insulin resistance, oxidative stress, and inflammation associated with diabetes can negatively impact the endothelium [1]. In recent times, endothelial dysfunction gained focused attention due to its critical role in the onset and progression of atherosclerosis as well as being an early predictive factor for cardiovascular events [2].
Inflammatory cytokines cause an increased expression of cellular adhesion molecules that are considered as a novel diagnostic marker as well as a therapeutic target for preclinical atherosclerosis [3].

Being back to nature, several experimental and clinical studies demonstrated the positive effect of herbal medicine such as Salvia miltiorrhiza Bunge and Radix Puerariae that are 
two frequently prescribed herbs in traditional Chinese medicine on endothelial dysfunction [4, 5]. Nigella sativa $L$. (NS), commonly known as black seed or black cumin in English, is a herbaceous plant that belongs to a big family called Ranunculaceae. Thymoquinone is the major pharmacologically active constituent of $N S$ and contributes to its several beneficial therapeutic effects [6]. NS is known for its miraculous healing properties such as antidiabetic, anti-hyperlipidemic, anti-convulsant, and cardioprotective effects [7]. These effects are mainly attributed to its role in improving oxidative stress, attenuation of inflammation, and modulation of biological activities involved in different pathological conditions [8].

It has become increasingly apparent in the literature from experimental animal studies that $N S$ has a potential ameliorative effect on endothelial dysfunction [9, 10]. This could be mediated through the upregulation of endothelial nitric oxide synthase while downregulating cell adhesion molecules and the oxidized low-density lipoprotein receptor-1 expression [11]. Also, NS can enhance endothelium-mediated vasorelaxant effect through restoring vasodilating compounds such as endogenous nitric oxide and endothelium-derived hyperpolarizing factor [12]. Thus, regulating the expression of adhesion molecules could be one of the critical mechanisms that are involved in the ameliorative effect of $N S$ on endothelial dysfunction [13].

It is worthy to mention that the effect of black seed oil on cell adhesion molecules and thus ameliorating endothelial dysfunction, in addition to its impact on QOL of type 2 diabetic patients has not been investigated up to the date of presenting this research article.

\section{Materials and Methods}

\subsection{Setting and Participants}

All patients presenting to the outpatient
Internal Medicine and Endocrinology Department of Ain Shams University Hospitals in Cairo, Egypt were assessed for eligibility. The study was registered in www.ClinicalTrials.gov (NCT03959306, May 2019) and approved by Research Ethics Committee for Experimental and Clinical Studies, Faculty of Pharmacy, Ain Shams University (approval number: 47) and conducted following the 1964 Declaration of Helsinki.

Patients that met the following requirements were enrolled into the study: age above 18 years, presence of type 2 diabetes mellitus (T2DM) for at least six months and was diagnosed according to American Diabetes Association (ADA) criteria: Standards of Medical Care in DiabetesJanuary 2019. On the other hand, patients were ruled out if they had any of the following criteria: candidates for insulin therapy, serious long-term diabetes complications, unstable coronary artery disease, cardiac arrhythmia or congestive heart failure, uncontrolled hypertension or recent stroke, presence of malignancy, chronic kidney disease or chronic liver disease. Participants should not have taken any intervention with black seed oil or any other herbal supplement within the last two months that precede the study. Signed informed consent was obtained from every patient before being enrolled in the study.

\subsection{Study Design}

This study was a prospective, randomized, placebo-controlled, double-blinded study. A total of 56 patients were blindly randomized either to the intervention or control group using computerized software (QuickCalcs - GraphPad Software). The intervention group received 1800 $\mathrm{mg} /$ day of black seed oil (Nigella sativa L. seed oil) soft gelatin capsule (900 mg twice daily) under the trade name of Baraka 450mg ${ }^{\circledR}$, Pharco Pharmaceutical, Cairo, Egypt. To assure the double blindness, the control group received identical placebo soft gelatin capsules with the 
same color and appearance for 3 months. All patients were under the same standard pharmacological treatment for the management of type 2 diabetes. Patients were followed up by making phone calls every week and asking them to visit the clinic every 10 days to refill their bottles that were previously prepared and numbered by an investigator with no clinical involvement in the trial. Patients were advised to report any undesirable effects in the provided adverse effects reporting sheet and were allowed to contact the investigator immediately. Both the principal investigator and study participants were blinded.

\subsection{Blood Sampling and Serum Parameters Measurement}

Serum samples were collected at the beginning and end of the study from each patient after $10-12 \mathrm{~h}$ of fasting. Serum samples were divided into two parts. One part of the serum sample was analyzed immediately for fasting blood glucose (FBG), glycated hemoglobin (HbA1c), full lipid profile, kidney and liver functions (serum creatinine $(\mathrm{sCr})$, blood urea nitrogen (BUN), aspartate aminotransferase (AST) and alanine aminotransferase (ALT) levels), while the other part was stored at -80 until the time of assay for high sensitivity creactive protein (hsCRP) and serum soluble intercellular adhesion molecule-1 (sICAM-1).

Ten healthy volunteers were recruited to determine the normal levels of hsCRP and sICAM-1 in diabetes-free, age, and sex-matched healthy people.

hsCRP (DRG International Inc., USA) and sICAM-1 (bio-techne company, Minneapolis, USA) commercial kits were used in the current study. hsCRP and sICAM-1 were measured by quantitative enzyme-linked immunoassay techniques. All other blood sample parameters were determined using the commercial kits
(Stanbio Laboratory, USA).

\subsection{Quality of Life (QOL) Assessment}

Patients of both groups were surveyed and their QOL was assessed at the beginning of the study and after three months follow-up period using an Arabic validated version of the Diabetes-39 questionnaire that is composed of five major domains that are affected by the presence of diabetes [14].

\subsection{Statistical Analysis}

IBM SPSS $^{\circledR}$ Statistics version 22 (IBM $^{\circledR}$ Corp., Armonk, NY, USA) was used for statistical analysis. Numeric data were checked for normality using the Shapiro-Wilk test. Qualitative data were examined by using Fisher's exact test. Comparison of quantitative data between the study groups was done using either the Student t-test or Mann-Whitney test. Comparison of two consecutive measures of numerical variables was done using either paired t-test or Wilcoxon-signed rank test as appropriate. Due to multiple comparisons, $p$ values were corrected using the Bonferroni method. Comparison of the percent change of parameters was calculated using the MannWhitney test. The Spearman-rho method was used to test correlations between numerical variables. All tests were two-tailed. $p<0.05$ was considered significant.

The sample size was calculated based on an early work done by Satoh and his colleagues about the effect of alpha-glucosidase inhibitor, voglibose, on biomarkers of oxidative stress and sICAM-1 in obese patients with type 2 diabetes [15]. Considering the effect size of $N S$ on sICAM-1 in diabetic patients is moderate (0.2). A total sample size of fifty patients (25 in each group) was required at an alpha level of 0.05 and a power of $80 \%$. The sample size was determined using the $\mathrm{G}^{*}$ Power $^{\odot}$ software (Institut für Experimentelle Psychologie, Heinrich Heine 
Universität, Düsseldorf, Germany) version fulfilled the eligibility criteria and were 3.1.9.2. randomized into the study groups. Throughout

\section{Results}

\subsection{Participants, Study Flow and Demographics} the study, 6 patients were dropped out due to different reasons as illustrated in Fig. 1. Patients

From May to December 2019, 81 patients were assessed for eligibility. Only 56 patients who participated and completed the study were $44(88 \%)$ females and $6(12 \%)$ males. No significant differences were found between the study groups regarding demographics (Table 1).

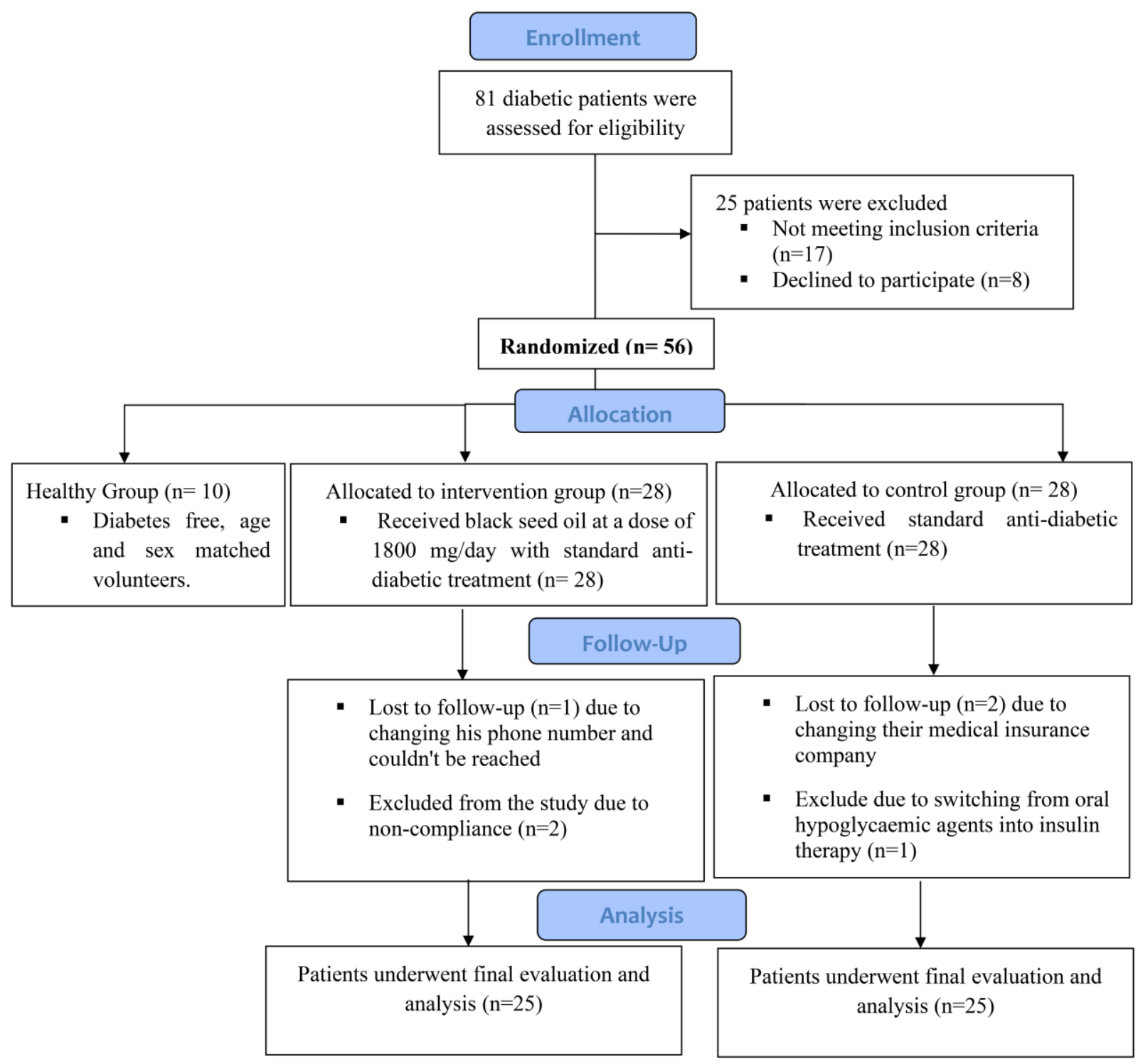

Fig. 1. Flow chart describing the study according to CONSORT guidelines 
Table 1. Demographic data of the study participants

\begin{tabular}{lccc}
\hline Variable & $\begin{array}{c}\text { Intervention group } \\
(\mathrm{N}=25)\end{array}$ & $\begin{array}{c}\text { Control group } \\
(\mathrm{N}=25)\end{array}$ & $\begin{array}{c}\text { Between-group } \\
\text { comparison }(p \text {-value })\end{array}$ \\
\hline Sex number (\%) & $3(12.0 \%)$ & $3(12.0 \%)$ & \\
Male & $22(88 \%)$ & $22(88 \%)$ & $1.000^{\mathrm{a}}$ \\
Female & $47.3(3.8)$ & $47.8(2.8)$ & $0.643^{\mathrm{b}}$ \\
Age Mean (SD) (years) & & & $0.658^{\mathrm{b}}$ \\
$\begin{array}{l}\text { Duration of diabetes } \\
\text { Mean (SD) (years) }\end{array}$ & $6.6(2.0)$ & $6.3(2.5)$ & \\
\hline
\end{tabular}

Data are expressed as mean and standard deviation (SD) or percentage (\%), $* p \leq 0.05$ is significant. ${ }^{\text {a }}$ between groups comparison using Fisher's exact test; ${ }^{b}$ between groups comparison using unpaired t-test; N, number of subjects.

\subsection{Effect on Metabolic Parameters}

No significant differences were documented between the study groups regarding baseline characteristics. The high-density lipoprotein (HDL) level was higher in the intervention group 47.360 (7.4548) vs 42.520 (6.5008) $\mathrm{mg} / \mathrm{dL}$ in the control group but it was not statistically significantly different after applying Bonferroni correction (corrected $p$-value $=0.072$ ) as illustrated in (Table 2).

When comparing the difference between the study groups at the end of the study, it is apparent from the results presented in (Table 2) that there was a statistically significant decrease concerning HbA1c ( $p=0.004)$ and triglycerides (TG) ( $p=$ 0.008 ), while, there were a statistically significant increase in HDL $(p=0.004)$ levels. Furthermore, a comparison of percent change among the study groups showed a significant difference regarding the levels of HbA1c ( $p=0.009)$, total cholesterol

\subsection{Correlations Between sICAM-1 Levels} and Glycemic Control, Lipid Profile Parameters and Inflammatory Markers

A strong negative correlation was found among sICAM-1 and HDL levels, while strong positive correlations were found among hsCRP, FBG, HbA1c, and sICAM-1 levels in all diabetic patients after 12 weeks (Fig. 2).

\subsection{Impact on QOL}

The study groups were comparable regarding
(TC) $(p=0.005)$, and TG $(p=0.047)$.

\subsection{Effect on Inflammatory and Endothelial Dysfunction Markers}

Compared to age and sex-matched healthy volunteers $(n=10)$, baseline hsCRP levels were statistically significantly higher in patients of both study groups 4.5 (3.6-5.1) compared to healthy volunteers $0.8 \quad(0.7-1.0) \quad \mathrm{mg} / \mathrm{L}$ with $(p<0.001)$. Also, sICAM-1 levels were significantly elevated in diabetic patients 311.2 (256-345) vs. 119 (110-134) ng/mL in healthy volunteers with $(p<0.001)$.

At baseline, there was no statistically significant difference regarding hsCRP and sICAM-1 between the study groups. Comparison of percent change among the study groups showed a significant difference regarding the levels of hsCRP $(p=0.003)$ and sICAM-1 $(p=$ 0.018) as illustrated in (Table 3).

the five QOL domains at baseline. Diabetes control domain scores were reduced from 70.8 (69.4-73.6) at baseline to $65.3(63.9-70.8)$ at the end of the study in the intervention group with $p=$ 0.012. Additionally, a comparison of percent change among the study groups showed a significant difference regarding diabetes control domain scores $(p=0.004)$. While no significant differences were observed in the other four domains' scores (Table 4). 
Table 2. Comparison of the anthropometric and biochemical parameters of study participants

\begin{tabular}{|c|c|c|c|}
\hline Parameter & $\begin{array}{l}\text { Intervention group } \\
\quad(\mathrm{N}=25)\end{array}$ & $\begin{array}{c}\text { Control group } \\
(\mathrm{N}=25)\end{array}$ & $p$-Value ${ }^{\text {a }}$ \\
\hline BMI-0 $\left(\mathrm{kg} / \mathrm{m}^{2}\right)$ Mean (SD) & $30.716(2.6418)$ & $29.367(2.9088)$ & 0.368 \\
\hline BMI-End $\left(\mathrm{kg} / \mathrm{m}^{2}\right)$ Mean (SD) & $30.042(2.6721)$ & $28.980(2.7897)$ & 0.704 \\
\hline$p$-Value ${ }^{\mathrm{b}}$ & $0.004 *$ & 0.267 & \\
\hline BMI -change (\%) Median (IQR) & $-2.7(-3.9--1.3)$ & $-2.7(-4.1-2.4)$ & 0.593 \\
\hline FBG-0 (mg/dL) Mean (SD) & $214(60.3504)$ & $220.040(70.6266)$ & 0.747 \\
\hline FBG-End (mg/dL) Mean (SD) & $179.840(53.293)$ & $200.040(76.6814)$ & 0.285 \\
\hline$p$-Value ${ }^{\mathrm{b}}$ & $0.044 *$ & 0.200 & \\
\hline FBG -change (\%) Median (IQR) & $-18.4(-39.4-7)$ & $-11.7(-24.8-2.7)$ & 0.628 \\
\hline HbA1c-0 (\%) Mean (SD) & $8.824(0.9369)$ & $9.248(1.1244)$ & 0.616 \\
\hline HbA1c-End (\%) Mean (SD) & $7.988(0.8217)$ & $9.012(1.1526)$ & $0.004 *$ \\
\hline$p$-Value ${ }^{\mathrm{b}}$ & $<0.001 *$ & 0.576 & \\
\hline HbA1c-change (\%) Median (IQR) & $-10.3(-15--3.5)$ & $-2.6(-9.1-2.7)$ & $0.009 *$ \\
\hline TC-0 (mg/dL) Mean (SD) & $193.280(33.2698)$ & $196.760(35.2080)$ & 0.721 \\
\hline TC-End (mg/dL) Mean (SD) & $180(29.858)$ & $195.160(33.3175)$ & 0.388 \\
\hline$p$-Value ${ }^{\mathrm{b}}$ & $<0.001 *$ & 0.530 & \\
\hline TC- change (\%) Median (IQR) & $-7.3(-11.8-2)$ & $-2.9(-4.8-1.6)$ & $0.005^{*}$ \\
\hline TG-0 (mg/dL) Mean (SD) & $132.720(51.4519)$ & $143.640(44.4915)$ & 0.426 \\
\hline TG-End (mg/dL) Mean (SD) & $104.120(30.333)$ & $138.880(42.8732)$ & $0.008 *$ \\
\hline$p$-Value ${ }^{\mathrm{b}}$ & $0.008^{*}$ & 0.232 & \\
\hline TG -change (\%) Median (IQR) & $-18.9(-25.4-1.6)$ & $-5.8(-9.2--0.7)$ & $0.047 *$ \\
\hline HDL-0 (mg/dL) Mean (SD) & $47.360(7.4548)$ & $42.520(6.5008)$ & 0.072 \\
\hline HDL-End (mg/dL) Mean (SD) & $52.280(6.6741)$ & $45.440(7.2863)$ & $0.004 *$ \\
\hline$p$-Value ${ }^{\mathrm{b}}$ & $<0.001 *$ & 0.060 & \\
\hline HDL- change (\%) Median (IQR) & $10.2(-4.2-24.4)$ & $4.9(-4.3-18)$ & 0.240 \\
\hline LDL-0 (mg/dL) Mean (SD) & $119.376(30.4241)$ & $125.512(33.1107)$ & 0.498 \\
\hline LDL-End (mg/dL) Mean (SD) & $106.896(30.808)$ & $121.944(32.756)$ & 0.404 \\
\hline$p$-Value ${ }^{\text {b }}$ & $0.004 *$ & 0.728 & \\
\hline LDL- change (\%) Median (IQR) & $-13.8(-20.5-0.6)$ & $-3.4(-7.2-3)$ & 0.056 \\
\hline AST -0 (U/L) Mean (SD) & $31.120(2.8624)$ & $30.640(3.7956)$ & 0.616 \\
\hline AST-End (U/L) Mean (SD) & $30.720(3.2853)$ & $30.040(3.1289)$ & 0.457 \\
\hline$p$-Value ${ }^{\mathrm{b}}$ & 0.322 & 0.228 & \\
\hline AST- change (\%) Median (IQR) & $-3.2(-5.9-5.1)$ & $-3.2(-5.7-3)$ & 0.900 \\
\hline ALT -0 (U/L) Mean (SD) & $28.480(7.6546)$ & $27.680(6.5046)$ & 0.692 \\
\hline ALT-End (U/L) Mean (SD) & $28.240(7.0017)$ & $28.040(5.6751)$ & 0.912 \\
\hline$p$-Value ${ }^{\mathrm{b}}$ & 0.736 & 0.640 & \\
\hline ALT -change (\%) Median (IQR) & $0(-7.1-10.7)$ & $4.9(-11.1-15)$ & 0.621 \\
\hline BUN-0 (mg/dL) Mean (SD) & $29.000(2.9861)$ & $28.640(3.8932)$ & 0.715 \\
\hline BUN-End (mg/dL) Mean (SD) & $28.600(3.8837)$ & $28.120(4.1162)$ & 0.673 \\
\hline$p$-Value ${ }^{\mathrm{b}}$ & 0.475 & 0.417 & \\
\hline BUN- change (\%) Median (IQR) & $-4(-7.4-7.4)$ & $-3.7(-8.8-6.9)$ & 0.884 \\
\hline $\mathbf{s C r - 0}(\mathrm{mg} / \mathrm{dL})$ Mean $(\mathrm{SD})$ & $0.9492(0.15171)$ & $0.9040(0.13687)$ & 0.274 \\
\hline sCr-End (mg/dL) Mean (SD) & $0.888(0.2166)$ & $0.860(0.1555)$ & 0.602 \\
\hline$p$-Value ${ }^{\mathrm{b}}$ & 0.82 & 0.344 & \\
\hline sCr-change $(\%)$ Median (IQR) & $-12.5(-25-12.5)$ & $-9.1(-12.5-10)$ & 0.509 \\
\hline
\end{tabular}

Data are expressed as mean and standard deviation (SD) or median and inter-quartile range (IQR), $* p \leq 0.05$ is significant. $p$ Value: "between groups comparison using unpaired t-test, -change: percent change calculated using Mann-Whitney test, $p$-Value: ${ }^{b}$ within group comparison using paired t-test. N, number of subjects; - 0 , baseline; BMI, body mass index; FBG, fasting blood glucose; HbA1c, glycated hemoglobin; TC, total cholesterol; TG, triglycerides; HDL, high-density lipoprotein; LDL, low-density lipoprotein; AST, aspartate aminotransferase; ALT, alanine aminotransferase; BUN, blood urea nitrogen; sCr, serum creatinine. 
Table 3. Values and statistical analysis of inflammatory and endothelial dysfunction markers of the study participants

\begin{tabular}{|c|c|c|c|}
\hline Parameter & $\begin{array}{l}\text { Intervention group }(\mathbf{N}=25) \\
\text { Median }(I Q R)\end{array}$ & $\begin{array}{l}\text { Control group }(\mathrm{N}=25) \\
\text { Median (IQR) }\end{array}$ & $p$-Value ${ }^{a}$ \\
\hline hsCRP-0 (mg/L) & $4.3(3.5-4.8)$ & $4.7(3.9-5.2)$ & 0.317 \\
\hline $\begin{array}{l}\text { hsCRP-End (mg/L) } \\
p^{- \text {Value }}{ }^{\text {b }}\end{array}$ & $\begin{array}{l}3.2(2.5-5) \\
0.004^{*}\end{array}$ & $\begin{array}{l}4.5(3.5-5.4) \\
0.262\end{array}$ & 0.112 \\
\hline hsCRP- change (\%) & $-20(-34.6--5.6)$ & $-6(-9.7-6.4)$ & $0.003 *$ \\
\hline $\begin{array}{l}\text { sICAM 1-0 }(\mathrm{ng} / \mathrm{mL}) \\
\text { sICAM 1- End }(\mathrm{ng} / \mathrm{mL}) \\
p \text {-Value } \mathrm{b} \\
\text { sICAM 1- change }(\%)\end{array}$ & $\begin{array}{l}282(218-344) \\
245(184-291) \\
0.004 * \\
-15.2(-20.3--6)\end{array}$ & $\begin{array}{l}314(282.5-401) \\
334(251-375) \\
0.696 \\
-6.2(-11.2-3.9)\end{array}$ & $\begin{array}{l}0.244 \\
0.024^{*} \\
0.018^{*}\end{array}$ \\
\hline
\end{tabular}

Data are expressed as median and inter-quartile range (IQR), *p $\leq 0.05$ is significant.

$p$-Value: ${ }^{a}$ between-groups comparison using Mann-Whitney test, -change: percent change calculated using Mann-Whitney test,

$p$-Value: ${ }^{\mathrm{b}}$ within-group comparison using Wilcoxon-signed rank test. $\mathrm{N}$, number of subjects; -0, baseline; hsCRP, high sensitivity

c-reactive protein; sICAM-1, soluble intercellular adhesion molecule-1.

Table 4. Comparison of quality of life domain scores at baseline and after 3 months among the study groups

\begin{tabular}{|c|c|c|c|}
\hline Parameter & $\begin{array}{c}\text { Intervention group }(\mathbf{N}=25) \\
\text { Median }(I Q R)\end{array}$ & $\begin{array}{c}\text { Control group }(\mathrm{N}=25) \\
\text { Median }(\mathrm{IQR})\end{array}$ & $p$-Value ${ }^{a}$ \\
\hline \multicolumn{4}{|l|}{ Energy and mobility domain scores } \\
\hline at Baseline & $68.9(67.8-73.3)$ & $70(66.7-71.1)$ & 0.483 \\
\hline After 3 months & $67.8(63.3-72.2)$ & $67.8(65.6-70)$ & 0.838 \\
\hline$p$-Value ${ }^{\mathrm{b}}$ & 0.0680 & 0.385 & \\
\hline \multicolumn{4}{|l|}{ Energy and mobility domain scores percent } \\
\hline \multicolumn{4}{|l|}{ Diabetes control domain scores } \\
\hline at Baseline & $70.8(69.4-73.6)$ & $75(69.4-80.6)$ & 0.164 \\
\hline After 3 months & $65.3(63.9-70.8)$ & $75(69.4-80.6)$ & $0.004 *$ \\
\hline$p$-Value ${ }^{b}$ & $0.012 *$ & 0.408 & \\
\hline Diabetes control domain scores & $-5.7(-9.6--1.9)$ & $-1.7(-3.6-0)$ & $0.004 *$ \\
\hline \multicolumn{4}{|l|}{ Anxiety and worry domain scores } \\
\hline at Baseline & $75(66.7-79.2)$ & $79.2(66.7-87.5)$ & 0.551 \\
\hline After 3 months & $75(66.7-83.3)$ & $79.2(70.8-87.5)$ & 0.372 \\
\hline$p$-Value ${ }^{b}$ & 0.418 & 0.496 & \\
\hline \multicolumn{2}{|l|}{ Anxiety and worry domain scores } & $0.0(-4.5-11.1)$ & 0.065 \\
\hline \multicolumn{4}{|l|}{ Social burden domain scores } \\
\hline at Baseline & $70(63.3-73.3)$ & $70(63.3-76.7)$ & 0.458 \\
\hline After 3 months & $63.3(63.3-66.7)$ & $66.7(60-76.7)$ & 0.255 \\
\hline$p$-Value ${ }^{\mathrm{b}}$ & 0.596 & 0.892 & \\
\hline \multicolumn{4}{|l|}{ Social burden domain scores percent change } \\
\hline \multicolumn{4}{|l|}{ Sexual functioning domain scores } \\
\hline After 3 months & $38.9(16.7-55.6)$ & $50(27.8-61.1)$ & 0.964 \\
\hline$p$-Value ${ }^{\mathrm{b}}$ & 0.908 & 0.591 & \\
\hline $\begin{array}{l}\text { Sexual functioning domain scores } \\
\text { percent change }(\%)\end{array}$ & $0.0(-10-0.0)$ & $0.0(-10-16.7)$ & 0.651 \\
\hline
\end{tabular}

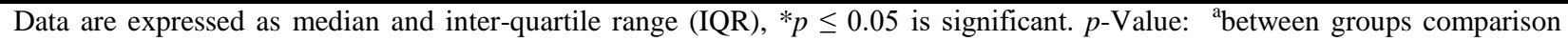
using Mann-Whitney test, -change: percent change calculated using Mann-Whitney test. $p$-Value: ${ }^{\mathrm{b}}$ within group comparison using Wilcoxon-signed rank test. N, number of subjects. 
A: Positive correlation between sICAM-1 levels and FBG levels in all diabetic patients after 3 months.

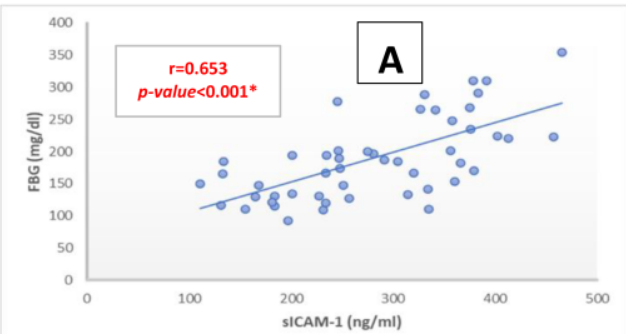

C: Negative correlation between sICAM-1 levels and HDL-C levels in all diabetic patients after 3 months.

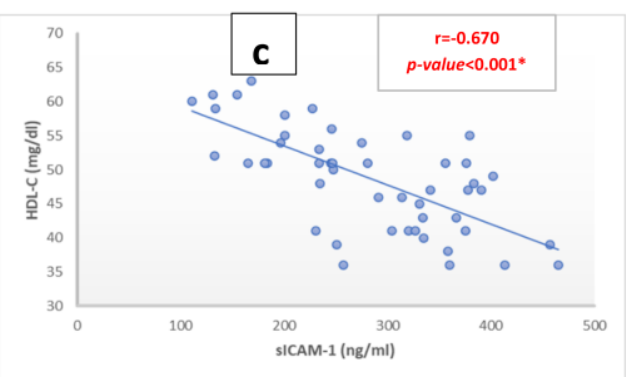

E: Positive correlation between sICAM-1 levels and TC levels in all diabetic patients after 3 months.

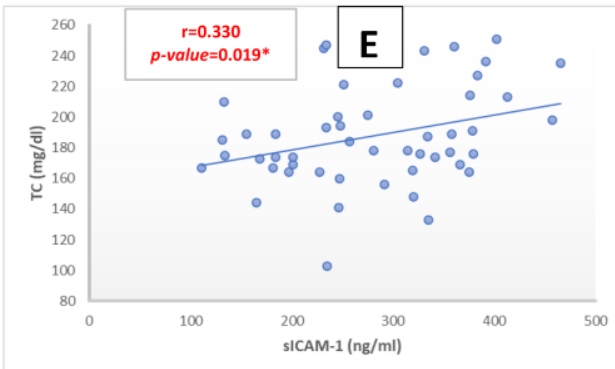

B: Positive correlation between sICAM-1 levels and HbA1c levels in all diabetic patients after 3 months.

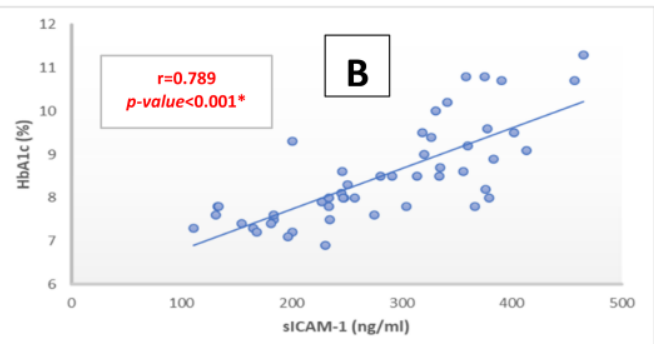

D: Positive correlation between sICAM-1 levels and hs-CRP levels in all diabetic patients after 3 months.

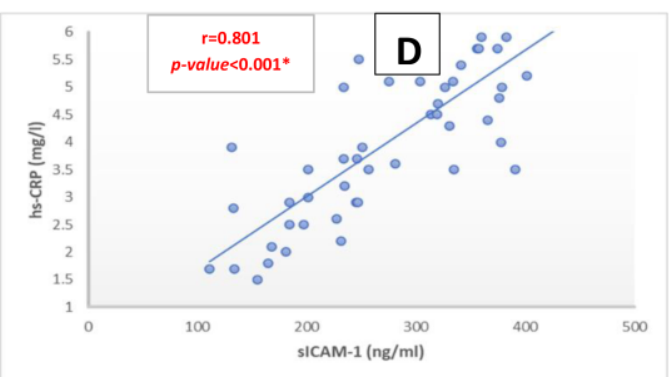

F: Positive correlation between sICAM-1 levels and TG levels in all diabetic patients after 3 months.

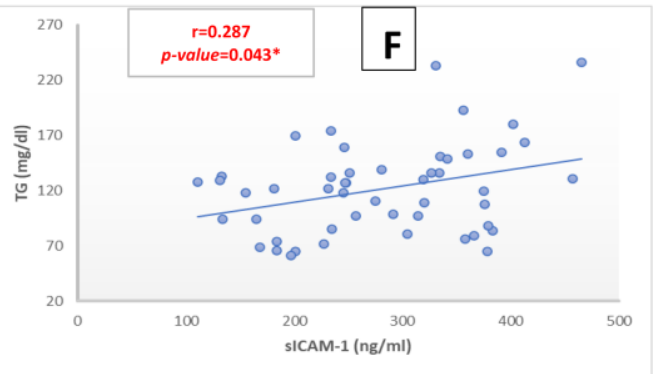

G: Positive correlation between sICAM-1 levels and LDL-C levels in all diabetic patients after 3 months.

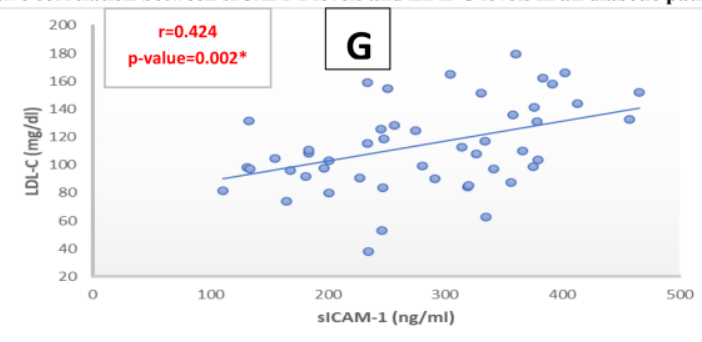

Fig. 2. Correlations between sICAM-1 and different metabolic and inflammatory parameters in both study groups after 12 Weeks

Statistical Test, spearman's rho; $* p \leq 0.05$ is significant. $\mathrm{r}$, correlation coefficient; sICAM-1, soluble intercellular adhesion molecule-1; FBG, fasting blood glucose; HbA1c, glycated hemoglobin; HDL-C, high-density lipoprotein-cholesterol; hs-CRP, high sensitivity c-reactive protein; TC, total cholesterol; TG, triglycerides; LDL-C, low-density lipoprotein-cholesterol. 


\subsection{Safety and Tolerability}

Concerning safety and tolerability of the intervention drug, it was found that $70 \%$ (35 patients) of all enrolled patients didn't show any adverse events throughout the study including 16 patients $(32 \%)$ from the intervention group and 19 patients (38\%) from the control group. Stomach upset and itching were the most frequent side effects among the intervention group. The occurrence of stomach upset and itching in the intervention group was $(16 \%$ and $12 \%)$ vs (4\% and 8\%) in the control group respectively. All of these symptoms disappeared after a few days from taking the capsules and did not result in discontinuation of the intervention drug or withdrawal from the study. Regarding Kidney functions and liver enzymes, within and between-group comparisons showed that there were no significant changes in their levels during the study period in both groups (Table 2).

\section{Discussion}

It has become obvious that CRP is a major contributing factor in platelet activation, atherosclerotic plaque formation as well as vascular remodeling [16]. Based on current evidence, CRP gained considerable attention as a useful biomarker in predicting cardiovascular events and mortality [17], retinopathy [18], and nephropathy in type 2 diabetic patients [19]. Similarly, with regards to cell adhesion molecules, a linear association was reported between elevations of ICAM-1 and diabetic renal, retinal, and macrovascular complications $[\mathbf{2 0}, \mathbf{2 1}]$. There is also a link between the levels of ICAM-1 and diabetic neuropathy [22]. So, both CRP and soluble adhesion molecules can be considered as attractive early predictors of diabetic complications and therapeutic targets for diabetic patients [23].

The effect of $N S$ on body composition and anthropometric indices was not consistent between studies [24]. In the present study, daily consumption of 1800 milligram $N S$ seed oil for 12 weeks decreased body weight and body mass index (BMI) significantly compared to baseline. However, between-group comparison and comparison of the percent change among the two groups were not significant. Anti-obesity properties of $N S$ could be explained by the decreased feeling of hunger and increased fullness, soluble fibers content, and basal metabolic rate level [24]. The current study results are in line with a previous study that documented the same findings [25].

In the current study, $N S$ oil significantly decreased FBG level by $18.4 \%$ compared to baseline, but it was not significant between the study groups. A previous study failed to improve FBG with the use of 1g/day dose, while it reported a significant improvement with 2 and 3 g/day doses [26]. Also, the administration of NS at a dose of $2 \mathrm{~g} /$ day in hyperlipidemic patients had no significant effect on FBG [27]. Moreover, a recent study reported no significant effect on FBG in metabolic syndrome patients [28]. This could be explained by the variability in dosages, duration of diabetes, last meal content, physical activity, stress, and diseases of study participants that could affect FBG level. It was found that $2 \mathrm{~g}$ of $N S$ for a period of 3 months and up to 1 year is the optimum dose to improve glycemic parameters [29]. The glucose-lowering effect of $N S$ could be mediated through its effect on the adenosine monophosphate-activated protein kinase pathway, which in turn increases insulin sensitivity and the oxidation of fatty acid, the synthesis of glucose transporter type 4, and peroxisome proliferator-activated receptor- $\gamma$ (PPAR- $\gamma)$ activity [30]. This current work demonstrated a significant decrease in the level of $\mathrm{HbA} 1 \mathrm{c}$, similar to the majority of previous studies [29].

Disturbances in lipid panel, elevated levels of 
TC, TGs, low-density lipoprotein (LDL), while a decreased level of HDL, are commonly seen in diabetic patients leading to an increased risk of atherosclerosis [31]. Previous studies reported different effects of NS on lipid parameters. The majority of studies showed a positive effect on plasma concentrations of TC, LDL, and TG, while more controversial results were reported regarding HDL [32]. In the present work, a significant reduction in the level of TC and TG by $7.3 \%$ and $18.9 \%$ respectively was observed in the intervention group. Also, NS oil decreased the level of LDL by $13.8 \%$, while it increased the level of HDL by $10.2 \%$ in the intervention group without reaching a statistical significance between the study groups. The hypolipidemic effect of $N S$ could be explained by its role in PPAR- $\gamma$ activation, up-regulation of LDL receptors which increases the clearance of LDL, reduction of cholesterol de novo synthesis, and inhibition of lipid peroxidation [33].

It was observed in the present study that hsCRP and sICAM-1 levels were elevated in diabetic patients compared to healthy volunteers, which are following previous studies that demonstrated the increased level of these markers in diabetic patients and their association with future diabetic complications and mortality [20, 23]. At the current work, a statistically significant reduction in hsCRP levels in the intervention group was found following randomized controlled trials which demonstrated the beneficial effect of $N S$ on the CRP level of patients with different disease states [34]. On the contrary, a recent meta-analysis failed to demonstrate any beneficial effect for $N S$ on the CRP level [32]. Inhibition of cyclooxygenase and lipoxygenase pathways, thus decreasing the level of pro-inflammatory cytokines, is the major mechanism contributing to $N S$ anti-inflammatory properties. In addition, it can suppress inflammation by decreasing body weight, scavenging reactive oxygen species, and increasing the activity of antioxidant enzymes [34].

The effect of NS on adhesion molecules in type 2 diabetic patients is still unexplored yet. The current study was the first clinical trial to investigate the effect of $N S$ on soluble adhesion molecules in type 2 diabetic patients. NS demonstrated a significant decrease in SICAM-1 levels of the intervention group compared to the baseline and control group which might prove the potential protective effect of black seed oil against diabetic vascular complications. Strong positive correlations between sICAM-1 levels and FBG, HbA1c, and hsCRP were found, while there was a negative correlation between SICAM1 and HDL levels. Similarly, previous studies reported a positive correlation between ICAM-1 and hsCRP [35], as well as HbA1c and ICAM-1 levels [36]. Furthermore, in diabetic patients with renal complications, there was an increased expression of profibrotic genes (ICAM-1) that positively correlated with $\mathrm{HbA} 1 \mathrm{c}$ and CRP indicating their role in the pathogenesis of diabetic nephropathy [37]. Moreover, our results are following a previous study that demonstrated a decreased expression of ICAM-1 with HDL [38].

$N S$ is a safe and well-tolerated herbal medicine. Our results are following previous studies that reported the potential safety and nontoxic effect of $N S$ in type 2 diabetic patients [26]. However, some previous reports documented undesirable side effects with high doses of $N S$ use, such as; indigestion, anorexia, nausea, diarrhea, stomachache, allergies, and eczema [34].

Poor glycemic control and its related diabetic complications have a great burden on the healthrelated QOL of those patients. The diabetes-39 questionnaire is a reliable multidiscipline diabetes-specific questionnaire that has been extensively used in diabetic patients with 
different demographic and clinical characteristics, ethnicity, gender, age, or level of education [39]. In the current study, patients treated with black seed oil experienced a statistically significant improvement in the diabetes control domain that may be related to the improvement of glycemic indices, lipid profile, and inflammatory markers in the intervention group. Energy and mobility, social burden, as well as anxiety and worry domains were improved but without reaching statistical significance that may need higher doses and a longer duration of time to be more obvious. Previous studies examined the effect of $N S$ on patients' QOL in different disease states [40], but there is no study in the same field of diabetes to compare with.

\section{Conclusions}

The current study shows that hsCRP and ICAM-1 are elevated in diabetic patients which increases their risk for diabetic complications. The administration of black seed oil with its proven antioxidant and anti-inflammatory properties decreased the level of both markers of vascular inflammation. Moreover, black seed oil was superior to standard treatment alone in improving metabolic parameters.

\section{Recommendations}

Since this is the first study conducted to study the effect of NS on endothelial dysfunction of type 2 diabetic patients, further multicenter trials with higher doses and for a longer time are needed to be performed to support current promising results.

\section{Declarations}

\section{Ethics approval}

All procedures performed were following the ethical standards of the Ethical Committee of Faculty of Pharmacy-Ain Shams University (approval number 47) and with the principles laid down in the the1964 Helsinki declaration. The study was registered in www.ClinicalTrials.gov (NCT03959306, May 2019).

\section{Consent to participate}

Informed consent was obtained from all patients for being included in the study.

\section{Consent to publish}

Not applicable.

\section{Availability of data and materials}

The datasets generated during and/or analyzed during the current study are available from the corresponding author on reasonable request.

\section{Competing interests}

The authors declare that they have no conflict of interest.

\section{Funding statement}

No funding source was received.

\section{Authors' contributions}

Amany Talaat Elgarf, Sara Mahmoud Shaheen, Maram M. Aboromia, and Nagwa A. Sabri contributed to the conceptualization and methodology of the study as well as writingreview and editing the final manuscript. Amany Talaat Elgarf collected participants' data, performed the statistical analysis, and wrote the original draft of the manuscript. Sara Mahmoud Shaheen, Maram M. Aboromia, and Nagwa A. Sabri were responsible for the supervision of all the study aspects. All authors contributed to manuscript revision, read, and approved the submitted version.

\section{Acknowledgments}

$\mathrm{We}$ are thankful to the patients who participated and completed this study, as well as the staff of the Internal Medicine Department of Ain Shams University hospitals for their 
assistance in patients' recruitment.

\section{References}

1. Kaur R, Kaur M, Singh J. Endothelial dysfunction and platelet hyperactivity in type 2 diabetes mellitus: molecular insights and therapeutic strategies. Cardiovasc Diabetol. 2018;17(1):121. doi:10.1186/s12933-018-0763-3.

2. Takeda Y, Matoba K, Sekiguchi K, Nagai Y, Yokota $\mathrm{T}$, Utsunomiya $\mathrm{K}$ et al. Endothelial dysfunction in diabetes. Biomedicines. 2020;8(7):182. doi:10.3390/biomedicines8070182.

3. Rashad NM, Amal S, Abomandour HG, Aboelfath AMK, el Sayed Rafeek M, Badr MS et al. Intercellular adhesion molecule-1 expression and serum levels as markers of preclinical atherosclerosis in polycystic ovary syndrome. $\mathrm{J}$ Ovarian Res. 2019;12(1):1-12. doi:10.1186/s13048-019-0566-5. .

4. Oduro PK, Fang J, Niu L, Li Y, Li L, Zhao X et al. Pharmacological management of vascular endothelial dysfunction in diabetes: TCM and western medicine compared based on biomarkers and biochemical parameters. Pharmacol Res. 2020;158(6): 104893 . doi:10.1016/j.phrs.2020.104893.

5. Zhao W, Yuan Y, Zhao H, Han Y, Chen X. Aqueous extract of Salvia miltiorrhiza BungeRadix Puerariae herb pair ameliorates diabetic vascular injury by inhibiting oxidative stress in streptozotocin-induced diabetic rats. Food Chem Toxicol. 2019;129 (2019):97-107. doi:10.1016/j.fct.2019.04.018. Epub 2019 Apr 29.

6. Dajani EZ, Shahwan TG, Dajani NE. Overview of the preclinical pharmacological properties of Nigella sativa (black seeds): a complementary drug with historical and clinical significance. J Physiol Pharmacol. 2016;67(6):801-817.

7. Yimer EM, Tuem KB, Karim A, Ur-Rehman N, Anwar F. Nigella sativa L. (Black Cumin): A Promising Natural Remedy for Wide Range of Illnesses. Evid Based Complement Alternat Med. 2019;2019:1528635. doi:10.1155/2019/1528635.

8. Hannan MA, Rahman MA, Sohag AAM, Uddin MJ,
Dash R, Sikder MH et al. Black Cumin (Nigella sativa L.): A Comprehensive Review on Phytochemistry, Health Benefits, Molecular Pharmacology, and Safety. Nutrients. 2021;13(6):1784. doi:10.3390/nu13061784.

9. Abbasnezhad A, Niazmand S, Mahmoudabady M, Soukhtanloo M, Rezaee SA, Mousavi SM. Nigella sativa seed decreases endothelial dysfunction in streptozotocin-induced diabetic rat aorta. Avicenna J Phytomed. 2016;6(1):67-76.

10. Ahmad A, Khan RM, Alkharfy KM. Effects of selected bioactive natural products on the vascular endothelium. J Cardiovasc Pharmacol. 2013;62(2):111-121. doi:10.1097/FJC.0b013e3182927e47.

11. Abbasnezhad A, Niazmand S, Mahmoudabady M, Rezaee SA, Soukhtanloo M, Mosallanejad R et al. Nigella sativa L. seed regulated eNOS, VCAM-1 and LOX-1 genes expression and improved vasoreactivity in the aorta of diabetic rat. $\mathrm{J}$ Ethnopharmacol. 2019;228:142-147. doi:10.1016/j.jep.2018.09.021.

12. Idris-Khodja N, Schini-Kerth V. Thymoquinone improves aging-related endothelial dysfunction in the rat mesenteric artery. Naunyn Schmiedebergs Arch Pharmacol. 2012;385(7):749-758. doi:10.1007/s00210-012-0749-8.

13. Mohebbati R, Abbasnezhad A. Effects of Nigella sativa on endothelial dysfunction in diabetes mellitus: A review. J Ethnopharmacol. 2020;252:112585. doi:10.1016/j.jep.2020.112585.

14. Khader YS, Bataineh S, Batayha W. The Arabic version of Diabetes-39: psychometric properties and validation. Chronic Illn. 2008;4(4):257-263. doi:10.1177/1742395308100647.

15. Satoh N, Shimatsu A, Yamada K, Aizawa-Abe M, Suganami T, Kuzuya $\mathrm{H}$ et al. An alpha-glucosidase inhibitor, voglibose, reduces oxidative stress markers and soluble intercellular adhesion molecule 1 in obese type 2 diabetic patients. Metabolism. 2006;55(6):786-793. doi:10.1016/j.metabol.2006.01.016.

16. Badimon L, Peña E, Arderiu G, Padró T, Slevin $\mathrm{M}$, Vilahur $\mathrm{G}$ et al. C-Reactive Protein in 
Atherothrombosis and Angiogenesis. Front Immunol. 2018;9:430. doi:10.3389/fimmu.2018.00430.

17. Tian R, Tian M, Wang L, Qian H, Zhang S, Pang $\mathrm{H}$ et al. C-reactive protein for predicting cardiovascular and all-cause mortality in type 2 diabetic patients: A meta-analysis. Cytokine. 2019;117:59-64. doi:10.1016/j.cyto.2019.02.005.

18. Song J, Chen S, Liu X, Duan H, Kong J, Li Z. Relationship between C-Reactive Protein Level and Diabetic Retinopathy: A Systematic Review and Meta-Analysis. PLoS One. 2015;10(12):e0144406.

doi:10.1371/journal.pone.0144406.

19. Sinha SK, Nicholas SB, Sung JH, Correa A, Rajavashisth TB, Norris $\mathrm{KC}$ et al. hs-CRP Is Associated With Incident Diabetic Nephropathy: Findings From the Jackson Heart Study. Diabetes Care. 2019;42(11):2083-2089. doi:10.2337/dc182563.

20. Wołoszyn-Durkiewicz A, Myśliwiec M. The prognostic value of inflammatory and vascular endothelial dysfunction biomarkers in microvascular and macrovascular complications in type 1 diabetes. Pediatr Endocrinol Diabetes Metab. 2019;25(1):28-35. doi:10.5114/pedm.2019.84710.

21. Joy SS, Siddiqui K. Molecular and Pathophysiological Mechanisms of Diabetic Retinopathy in Relation to Adhesion Molecules. Curr Diabetes Rev. 2019;15(5):363-371. doi:10.2174/1573399814666181017103844.

22. Sempere-Bigorra M, Julián-Rochina I, Cauli O. Differences and Similarities in Neuropathy in Type 1 and 2 Diabetes: A Systematic Review. J Pers Med. 2021;11(3):230. doi:10.3390/jpm11030230.

23. Hegazy GA, Awan Z, Hashem E, Al-Ama N, Abunaji AB. Levels of soluble cell adhesion molecules in type 2 diabetes mellitus patients with macrovascular complications. J Int Med Res. 2020;48(4):300060519893858. doi:10.1177/0300060519893858.

24. Safi S, Razmpoosh E, Fallahzadeh H, Mazaheri M, Abdollahi N, Nazari M, et al. The effect of Nigella sativa on appetite, anthropometric and body composition indices among overweight and obese women: A crossover, double-blind, placebocontrolled, randomized clinical trial. Complement Ther Med. 2021;57:102653. doi:10.1016/j.ctim.2020.102653.

25. Badar A, Kaatabi H, Bamosa A, Al-Elq A, AbouHozaifa B, Lebda F et al. Effect of Nigella sativa supplementation over one year on lipid levels, blood pressure and heart rate in type-2 diabetic patients receiving oral hypoglycemic agents: a nonrandomized clinical trial. Ann Saudi Med. 2017;37(1):56-63. doi:10.5144/02564947.2017.56.

26. Bamosa AO, Kaatabi H, Lebdaa FM, Elq A, AlSultanb A. Effect of Nigella sativa seeds on the glycemic control of patients with type 2 diabetes mellitus. Indian J Physiol Pharmacol. 2010;54(4):344-354.

27. Sabzghabaee AM, Dianatkhah M, Sarrafzadegan N, Asgary S, Ghannadi A. Clinical evaluation of Nigella sativa seeds for the treatment of hyperlipidemia: a randomized, placebo-controlled clinical trial. Med Arch. 2012;66(3):198-200. doi:10.5455/medarh.2012.66.198-200

28. Mohtashami A. Effects of bread with Nigella sativa on blood glucose, blood pressure and anthropometric indices in patients with metabolic syndrome. Clin Nutr Res. 2019;8(2):138-147. doi:10.7762/cnr.2019.8.2.138.

29. Mahmoodi MR, Mohammadizadeh $\mathrm{M}$. Therapeutic potentials of Nigella sativa preparations and its constituents in the management of diabetes and its complications in experimental animals and patients with diabetes mellitus: A systematic review. Complement Ther Med. 2020;50:102391. doi:10.1016/j.ctim.2020.102391.

30. Tavakoli-Rouzbehani OM, Maleki V, Shadnoush M, Taheri E, Alizadeh M. A comprehensive insight into potential roles of Nigella sativa on diseases by targeting AMP-activated protein kinase: a review. DARU J of Pharm Sci. 2020;28(2):779-787. doi:0.1007/s40199-020-00376-3. 
31. Kothari V, Bornfeldt KE. A New Treatment Strategy for Diabetic Dyslipidemia? Diabetes. 2020;69(10):2061-2063. doi:10.2337/dbi20-0035.

32. Hallajzadeh J, Milajerdi A, Mobini M, Amirani E, Azizi S, Nikkhah E et al. Effects of Nigella sativa on glycemic control, lipid profiles, and biomarkers of inflammatory and oxidative stress: A systematic review and meta-analysis of randomized controlled clinical trials. Phytother Res. 2020;34(10):25862608. doi:10.1002/ptr.6708.

33. Pelegrin S, Galtier F, Chalançon A, Gagnol JP, Barbanel AM, Pélissier Y et al. Effects of Nigella sativa seeds (black cumin) on insulin secretion and lipid profile: A pilot study in healthy volunteers. Br J Clin Pharmacol. 2019;85(7):1607-1611. doi:10.1111/bcp.13922.

34. Tavakoly R, Arab A, Vallianou N, Clark CCT, Hadi A, Ghaedi E, et al. The effect of Nigella sativa L. supplementation on serum C-reactive protein: A systematic review and meta-analysis of randomized controlled trials. Complement Ther Med. 2019;45:149-155. doi:10.1016/j.ctim.2019.06.008.

35. El-Mesallamy $\mathrm{H}$, Suwailem S, Hamdy N. Evaluation of C-reactive protein, endothelin-1, adhesion molecule(s), and lipids as inflammatory markers in type 2 diabetes mellitus patients. Mediators Inflamm. 2007;2007:73635. doi:10.1155/2007/73635.

36. Ruszkowska-Ciastek B, Sokup A, Wernik T, Ruprecht Z, Góralczyk B, Góralczyk K et al. Effect of uncontrolled hyperglycemia on levels of adhesion molecules in patients with diabetes mellitus type 2. J Zhejiang Univ Sci B. 2015;16(5):355-361. doi:10.1631/jzus.B1400218.

37. Darwish NM, Elnahas YM, AlQahtany FS. Diabetes induced renal complications by leukocyte activation of nuclear factor $\kappa-\mathrm{B}$ and the expression of its regulated genes. Saudi J Biol Sci. 2021;28(1):541-549. doi:10.1016/j.sjbs.2020.10.039.

38. Muñoz-Vega M, Massó F, Páez A, VargasAlarcón G, Coral-Vázquez R, Mas-Oliva J, et al. HDL-Mediated Lipid Influx to Endothelial Cells
Contributes to Regulating Intercellular Adhesion Molecule (ICAM)-1 expression and eNOS Phosphorylation. Int J Mol Sci. 2018;19(11):3394. doi:10.3390/ijms 19113394.

39. Tonetto IFdA, Baptista MHB, Gomides DdS, Pace AE. Quality of life of people with diabetes mellitus. Rev Esc Enferm USP. 2019;53:e03424. doi:10.1590/S1980-220X2018002803424.

40. Nikkhah-Bodaghi M, Darabi Z, Agah S, Hekmatdoost A. The effects of Nigella sativa on quality of life, disease activity index, and some inflammatory and oxidative stress factors in patients with ulcerative colitis. Phytother Res. 2019;33(4):1027-1032. doi:10.1002/ptr.6296. 